\title{
Gestão da educação em sistemas municipais de ensino no Tocantins: tensionamento entre princípio e método democráticos
}

\section{Management of education in municipal systems of teaching in Tocantins: tensioning between democratic principle and method Gestión de la educación en sistemas municipales de enseñanza en Tocantins: tensionamiento entre principio y método democráticos}

ROSILENE LAGARES

Orcid iD: http://orcid.org/0000-0003-2959-5573 Universidade Federal do Tocantins - Campus de Palmas. KATIA CRISTINA FERREIRA CUSTÓDIO BRITO Orcid iD: http://orcid.org/0000-0001-8519-4884 Universidade Federal do Tocantins - Campus de Palmas

MEIRE LÚCIA ANDRADE DA SILVA

Orcid iD: http://orcid.org/0000-0002-1237-6422 Sistema Municipal de Ensino de Gurupi-Tocantins.

\begin{abstract}
Resumo: $\mathrm{O}$ artigo apresenta exame do quadro normativo e de condições político-institucionais em sistemas municipais de ensino no Tocantins para a gestão democrática no campo da educação pública e características das dinâmicas de participação em suas comunidades escolares. Trata-se de uma pesquisa de natureza bibliográfica, documental e de campo. Os resultados mostram a presença de princípios/espaços/mecanismos essenciais à gestão democrática nos sistemas. Todavia, desnuda o tensionamento entre o princípio e o método democráticos. Evidencia a necessidade de aprofundamentos conceituais.
\end{abstract}

Palavras-chave: Gestão democrática da educação. Políticas educacionais. Legislação educacional. Educação municipal.

\begin{abstract}
The article presents a review of the normative framework and political-institutional conditions in municipal education systems in Tocantins, for the democratic management in the field of public education and characteristics of the dynamics of participation in their school communities. It is a research of bibliographical, documentary and field nature. The results show the presence of principles/spaces/mechanisms essential to the democratic management in the systems. However, it strips the tension between the democratic principle and method. It shows the need for conceptual deepening.
\end{abstract}

Keywords: Democratic management of education. Educational policies. Educational legislation. Municipal education. 
Resumen: El articulo presenta el marco normativo y de condiciones político-institucionales en sistemas municipales de enseñanza en Tocantins para la gestión democrática en el campo de la educación pública y características de las dinámicas de participación en sus comunidades escolares. Se trata de una investigación de naturaleza bibliográfica, documental y de campo. Los resultados muestran la presencia de principios/espacios/mecanismos esenciales para la gestión democrática en los sistemas. Sin embargo, desnuda la tensión entre el principio y el método democráticos. Evidencia la necesidad de profundidades conceptuales.

Palabras clave: Gestión democrática de la educación. Políticas educativas. Legislación educativa. Educación municipal.

\section{INTRODUÇÃO}

Circunscrito ao tema da gestão democrática no campo da educação pública, neste artigo tem-se por objetivo examinar o quadro normativo e condições político-institucionais estabelecidas por governos municipais com sistemas municipais de ensino (SME) no Estado do Tocantins para a gestão democrática da educação pública no âmbito dos seus sistemas e características das dinâmicas de participação nas comunidades escolares nos municípios, entre os anos de 1997 a 2018.

O trabalho é um dos resultados da Pesquisa da Rede MAPA no Tocantins (Gestão democrática do ensino público: mapeamento das bases normativas e das condições político-institucionais dos sistemas municipais de ensino), em consonância com a pesquisa nacional (NARDI, 2014) desenvolvida no Subgrupo de Estudos, Pesquisa e Extensão em Educação Municipal da Universidade Federal do Tocantins (EpeEM/UFT), vinculado ao Núcleo de Estudos, Pesquisa e Extensão de Políticas Curriculares e Educativas (NEPCE), ao Observatório dos Sistemas e Planos de Educação no Tocantins (ObSPE) e à Associação Nacional de Política e Administração da Educação (Anpae) - diretoria Tocantins.

Trata-se de uma pesquisa assentada em revisão bibliográfica (LIMA; MIOTO, 2007); pesquisa documental (SHIROMA; CAMPOS; GARCIA, 2005), com análise de conteúdo de normas; e pesquisa de campo (DENZIN; LINCOLN, 2006), com aplicação de questionários semiestruturados junto a membros de conselhos municipais de educação (CME) dos municípios com SME, participantes da investigação.

A delimitação empírica da investigação compreende 36 municípios do estado do Tocantins ${ }^{1}$, situados em duas mesorregiões e em cinco microrregiões, como apresentado no Quadro 1 e na Figura 1.

O estado do Tocantins possui 139 municípios. 


\section{Quadro 1 - Universo de população da pesquisa, 2018}

\begin{tabular}{|c|c|c|c|c|}
\hline Item & Mesorregião & Microrregião & $\begin{array}{c}\text { Total de } \\
\text { municípios }\end{array}$ & Municípios com SME \\
\hline 1 & Ocidental & Araguaína & 17 & $\begin{array}{l}6 \\
\text { Araguaína, 2008; Colinas do Tocantins, } \\
\text { 2001; Muricilândia, 2013; Nova Olinda, 2005; } \\
\text { Palmeirante, 2011; Wanderlândia, } 2007 .\end{array}$ \\
\hline 2 & Ocidental & Miracema do Tocantins & 24 & $\begin{array}{c}7 \\
\text { Brasilândia, 2009; Fortaleza do Tabocão, } \\
\text { 2005; Goianorte, 2016; Guaraí, 2009; } \\
\text { Miracema, 2004; Miranorte, 2009; Presidente } \\
\text { Kennedy, } 1990 .\end{array}$ \\
\hline 3 & Ocidental & Rio Formoso & 13 & $\begin{array}{c}7 \\
\text { Araguaçu, 2008; Fátima, 2007; Formoso do } \\
\text { Araguaia, 2004; Lagoa da Confusão, 2017; } \\
\text { Nova Rosalândia, 2008; Paraíso, 2016; } \\
\text { Sandolândia, 2010. }\end{array}$ \\
\hline 4 & Oriental & Porto Nacional & 11 & $\begin{array}{c}6 \\
\text { Bom Jesus do Tocantins, 2006; Lajeado, } \\
\text { 2011; Palmas, 2004; Pedro Afonso, 2004; } \\
\text { Porto Nacional, 2007; Santa Maria do } \\
\text { Tocantins, 2010. }\end{array}$ \\
\hline 5 & Oriental & Dianópolis & 20 & $\begin{array}{c}10 \\
\text { Arraias, 2005; Combinado, 2006; 2017; } \\
\text { Dianópolis, 2002; Lavandeira, 1997; } \\
\text { Natividade, 1998; Novo Alegre, 2006; Ponte } \\
\text { Alta do Bom Jesus, 2017; Santa Rosa do } \\
\text { Tocantins, 2007; Taguatinga, 2006; Taipas do } \\
\text { Tocantins, 2009. }\end{array}$ \\
\hline TOTAL & 2 & 5 & 85 & 36 \\
\hline
\end{tabular}

Fonte: Arquivos Rede MAPA-TO (2015-2019).

\section{Figura 1-Microrregiões do Tocantins}

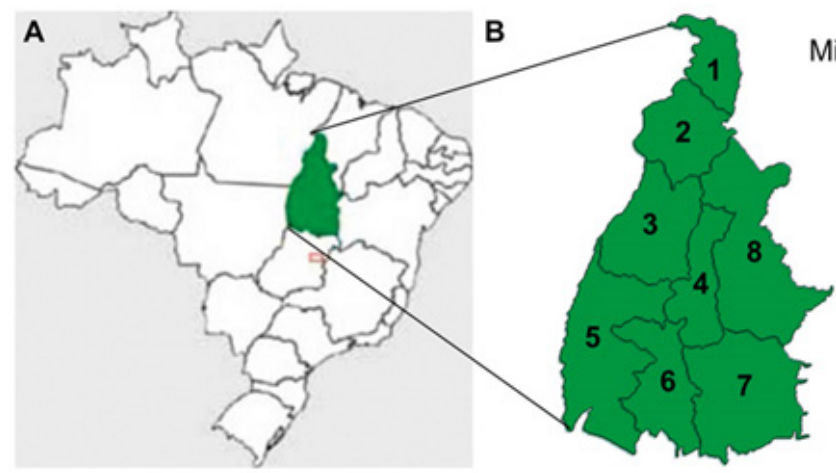

Microrregiões do Tocantins

1 - Bico do papagaio

2 - Araguaina

3 - Miracema

4 - Porto Nacional

5 - Rio Formoso

6 - Gurupi

7 - Dianópolis

8 - Jalapão

Fonte: http:/ /www.google.com.br. Acesso em: 10 de jun. 2019. 
A primeira etapa da pesquisa iniciou-se no segundo semestre de 2015, com a revisão bibliográfica, para aprofundamento teórico-conceitual; a pesquisa documental foi realizada em municípios com SME, com a coleta de documentos municipais que tivessem relação direta ou indireta com a gestão democrática, a partir do recorte histórico entre 1997 - primeiro ano de implementação da Lei de Diretrizes e Bases da Educação Nacional (LDB) nº 9.394 (BRASIL, 1996) - e 2018 - data recorte da pesquisa (NARDI, 2014).

Para a captação de informações e documentos, foram realizados contatos remotos por telefone, WhatsApp e e-mail, diretamente com os responsáveis pela educação nos municípios, no segundo semestre de 2015, mas com um baixo retorno dos pesquisados. Em 2016, realizou-se uma análise e interpretação dos Planos Municipais de Educação (PME) do Tocantins (LEMOS, 2017) e, em 2017, foram retomados os contatos remotos ${ }^{2}$. Em seguida, considerando o baixo retorno de respostas, decidiu-se pelo contato direto por telefone ${ }^{3}$ com os secretários municipais de Educação e/ou técnicos das Secretarias Municipais de Educação.

Também foram coletados dados e informações em sites oficiais, como das prefeituras, Portal da Transparência, da Secretaria de Estado da Educação do Tocantins (Seduc), do Conselho Estadual de Educação (CEE), da União Nacional de Conselhos Municipais de Educação (Uncme).

A segunda etapa da investigação deu-se a partir do segundo semestre de 2018, com a pesquisa de campo nas microrregiões, mediante a aplicação de questionários semiestruturados (REDE MAPA, 2018a, 2018b) junto a membros de Conselhos Municipais de Educação (CME) dos municípios que apresentaram leis de criação do SME, aprovadas até o ano de 2018. Após contatos por telefone e WhatsApp, solicitando a indicação de um membro representante do segmento docente e um membro representante da sociedade civil nos conselhos, os questionários foram encaminhados por e-mail aos sujeitos indicados.

A partir de uma ampla pesquisa, os documentos e as respostas aos questionários foram estudados, tomando-se como orientações a análise de conteúdo, sendo "um conjunto de técnicas de análise das comunicações, que utiliza procedimentos sistemáticos e objetivos de descrição do conteúdo das mensagens.” (BARDIN, 2009, p. 38).

2 Por solicitação direta da coordenação da pesquisa, pela Gerência de Apoio aos Sistemas Municipais de Ensino da Secretaria de Estado da Educação do Tocantins (Gam/Seduc) e a partir do diálogo e articulação com a União dos Dirigentes Municipais de Ensino - Seccional Tocantins (Undime), no mês de junho de 2017, com todos os 139 municípios do Tocantins. 
Bardin (2009) utiliza unidades de registro, sendo palavras, frases ou temas repetidos no decorrer do texto de diferentes documentos em análise que possibilitam identificar contradições ou convergências; unidades de contexto que, por sua vez, evidenciam características do cenário mais amplo; e a frequência, uma contagem das vezes em que determinada unidade de registro aparece no texto e que viabiliza, não só categorizá-la, mas com interpretação sistêmica e sistemática, depreender intencionalidades e concepções presentes na mensagem.

A partir dos pressupostos de Shiroma, Campos e Garcia (2005), os textos foram analisados minuciosamente para apreender as diretrizes municipais para a gestão democrática da educação, considerando-se o tempo histórico e o contexto em que foram produzidos, sendo confrontados entre si:

\begin{abstract}
Os textos são apenas ponto de partida, nossa meta não é fazer análise de discurso, mas compreender a política. [...] Tomamos os textos como produtos e produtores de orientações políticas. Os sentidos não são dados nos documentos, são produzidos; estão aquém e além das palavras que os compõem. Por isso, focamos não apenas um documento isoladamente, mas suas versões preliminares, textos complementares, assim como o contexto de influência e da produção dos textos, articulando níveis macro e micro de análise. Nessa perspectiva, um documento não é restrito a uma única e harmoniosa leitura. Pelo contrário, é aberto a releituras, não um objeto para consumo passivo, mas um objeto a ser trabalhado pelo pesquisador para produzir sentido. (p. 427).
\end{abstract}

A análise e a interpretação assentaram-se, também, em um referencial teórico que concebe e analisa a gestão democrática no campo da educação como um movimento histórico e contextualizado, e como fenômeno político, portanto, perpassada por disputas de sentido e poder (BORDIGNON; GRACINDO, 2008; SANDER, 2009; SOUZA, 2009); bem como não se encerrando nos processos de tomada de decisões e com vistas à emancipação humana; e não apenas um conjunto de métodos (espaços/ mecanismos/ instrumentos), que servem mais a um propósito burocrático e conservador.

\title{
GESTÃO DEMOCRÁTICA NO CAMPO DA EDUCAÇÃO: ELEMENTOS NORMATIVOS E CONCEITUAIS
}

A partir da promulgação da Constituição Federal de 1988 (art. 206), o país passou a contar com uma concepção de gestão assentada em ideais democráticos. Nesse tempo, a expressão "gestão democrática", conquistou notabilidade, sendo recepcionados nos anos 1990 pela Lei de Diretrizes e Bases da Educação Nacional (LDB, arts. $3^{\circ}$ e 14), restrita ao ensino; e, nos anos 2000, pelo Plano Nacional de Educação (PNE) (BRASIL, 2014), ampliada para a educação. 
Nessas circunstâncias, os estados, os municípios e o Distrito Federal, de forma a organizarem os seus sistemas de ensino, são obrigados a elaborar leis, institucionalizando os sistemas de ensino e disciplinando a gestão democrática da educação pública.

Entretanto, a expressão apresenta sentidos distintos, a depender da perspectiva teórica e política que os embasam. Em assim sendo, nesta pesquisa, tem-se por gestão democrática da educação o conceito definido por Bordignon e Gracindo (2008, p. 147), como sendo "o processo político-administrativo contextualizado, através do qual a prática social da educação é organizada, orientada e viabilizada." E, por gestão democrática da escola, as ideias de Souza (2009, p. 137), compreendendo "um processo político que é mais amplo do que apenas as tomadas de decisão e que é sustentado no diálogo e na alteridade, na participação ativa dos sujeitos do universo escolar, na construção coletiva de regras e procedimentos e na constituição de canais de comunicação [...]."

Como se lê, embora algumas perspectivas conceituais definam a gestão democrática no campo da educação como um aspecto técnico, para os autores, ela é, antes de tudo, um fenômeno político (BORDIGNON; GRACINDO, 2008; SANDER, 2009; SOUZA, 2009).

Para a sua materialização, a participação é um dos seus princípios fundamentais, demarcada nas normas nacionais (BRASIL, 1996, 2014). Todavia, considerando-se a polissemia do termo, importa demarcar que, neste texto, "participação" é concebida em uma perspectiva crítica, assentando-se em Freire (2011), que diferencia a participação compreendida como técnica de gestão, da concepção de participação sociopolítica. Na primeira, apresenta-se uma concepção que fundamenta as práticas institucionalizadas da educação:

[...] é entendida como "técnica de gestão" aplicada aos processos locais de execução das políticas educacionais. Essa concepção é propiciada pelas políticas de descentralização que mantém centralizado o poder de tomada de decisão, desconcentrando apenas as tarefas de execução que passam a requerer uma participação controlada e coesa com os processos estruturais da sociedade. Essa forma da participação, sinaliza-se um processo de reificação dos sujeitos sociais sem poder de decisão, que neste trabalho denominou-se participação reificada. (p. 8).

$\mathrm{Na}$ participação sociopolítica, “em contraposição [à técnica de gestão], encontra-se a concepção [...] de uma participação sócio-política com efetivo poder de decisão por parte dos sujeitos sociais do trabalho." (FREIRE, 2011, p. 8).

Como anota Freire (2011, p.64-65), a democracia exclui: 
A forma da democracia moderna configura-se pela exclusão das massas populares do processo substantivo de tomada de decisões devido à institucionalização formal da participação política no modo de representação da vontade popular, que se baseia, sobretudo, no direito ao voto nos processos eleitorais periódicos limitados pelas "regras do jogo democrático", previamente estabelecidas.

No que tange à institucionalização da educação municipal, há condições e desafios, fragilidades e potencialidades que permeiam a existência dos municípios e sua atuação na educação. Nesse movimento, um dos desafios é a materialização do princípio da gestão democrática (BRASIL, 1988), por meio de diversos instrumentos/ mecanismos/ espaços (BRASIL, 1996, 2014).

Considerando que "A história da educação revela que o campo educacional é uma arena de lutas em que seus atores vêm tratando de impor suas opções políticas e arbitrários culturais e suas legítimas categorias de percepção e apreciação", o campo da gestão educacional, como em outros, é fortemente marcado "por contradições, dissensos e dicotomias" (SANDER, 2009, p. 69), cuja disputa é acirrada entre os paradigmas de construção liberal e crítica. Nessa arena, "A gestão democrática é processo e enfrenta oposições tensionantes entre o experenciado historicamente, concepções coexistentes e a disputa na construção de outra realidade. Ante o esforço dessa construção e dilemas que dele originam, há estagnações, retrocessos e avanços.” (SILVEIRA; LAGARES, 2017, p. 1).

Busca-se, com essas observações, tratar a gestão democrática enquanto uma possibilidade de enfrentamento aos movimentos burocráticos e autoritários no campo da gestão, mas entendendo-a entre possibilidades e limites.

\section{QUADRO NORMATIVO E CONDIÇÕES INSTITUCIONAIS PARA A GESTÃO DEMOCRÁTICA DA EDUCAÇÃO}

Em se tratando de apreender o quadro normativo e condições políticoinstitucionais para a promoção da gestão democrática da educação pública, no âmbito dos $36 \mathrm{SME}$ pesquisados, foi analisado um vasto conjunto de documentos: Leis Orgânicas Municipais; leis dos Sistemas Municipais de Ensino; leis e decretos dos CME; leis dos planos municipais de educação; leis dos conselhos escolares (CE); leis dos Conselhos do Fundeb; leis de Planos de Carreiras; leis e decretos dos Fóruns Municipais de Educação; decretos de eleições de diretores; portarias de nomeações de equipes técnicas e comissões do PME; decretos e portarias de conferências municipais de educação. 
Comparando-se os municípios com leis de sistemas próprios e o número de habitantes, não há uma relação direta entre essas duas variáveis para definir municípios com ou sem leis de sistemas próprios, pois a quantidade de habitantes varia entre 177.517 a menos de 2 mil.

Os resultados mostram que há poucas diferenças entre as microrregiões do Estado, em se tratando do quadro normativo. Da análise da cronologia da institucionalização dos SME, embora o PNE revogado - lei no 10.172 (BRASIL, 2001) - não tenha sido implementado, pareceu que o documento estimulou esse processo, uma vez que reiterava atribuições aos sistemas de ensino dos municípios, e poucos sistemas foram criados logo após a aprovação da LDB (BRASIL, 1996, art. 11), que explicitou as três possibilidades de organização da educação em âmbito municipal: sistemas próprios de ensino; integrar-se ao sistema estadual de ensino; compor com o sistema estadual um sistema único de educação básica. Além disso, poucos foram criados ou alterados nos contextos do PNE vigente, lei no 13.005 (BRASIL, 2014), e da elaboração dos Planos Municiais de Educação (PME), sobretudo a partir de 2015.

Em se tratando da tipologia desses documentos, a análise demostrou que prevalece a lei, seguida do decreto e da portaria. E quanto a possíveis renovações, poucos municípios alteraram suas normas desde a criação dos sistemas. Dessas normas, poucas foram aprovadas entre os anos 2000 e 2010 e a maioria na segunda década do século XXI. Os objetos enfocados nesses outros documentos normativos da gestão da educação, no âmbito dos SME, são Conselho Municipal de Educação (CME); Fórum Municipal de Educação (FME); PME; Equipe Técnica e Comissão do PME; CE; Câmara Municipal de Educação Básica e o Conselho do Fundo de Manutenção e da Educação Básica (Fundeb), como Câmaras do CME; Plano de Carreira dos Profissionais da Educação (PCCR); eleições de diretores.

Como princípios de gestão democrática do ensino público, a análise das leis municipais demonstra que são recorrentes a autonomia das unidades de ensino, a descentralização das decisões e a participação social.

Nas normas complementares às leis dos SME, sobressaem como princípios de gestão democrática a participação e eleição direta de presidentes dos CME e a nomeação de conselheiros e presidentes de CME por prefeitos municipais, indicando que na disputa de concepções de gestão prevalece, nesses municípios, a construção liberal (SANDER, 2009).

Os espaços e mecanismos de participação definidos na legislação dos sistemas são: CME, FME, PME, nomeação da Equipe Técnica e Comissão do PME, CE, Conselho de Acompanhamento e Controle Social do Fundeb, Conselho Municipal de Alimentação Escolar e Comissão de Gestão do PCCR. 
Tomando como pressuposto as normas nacionais que dispõem sobre a gestão democrática da educação (BRASIL, 1988, 1996, 2014), nos municípios são apresentados importantes espaços/mecanismos/instrumentos, mas parcos, considerando-se a centralização das informações nos secretários municipais e a própria dificuldade desses sujeitos em identificar a existência ou não do sistema de ensino em seus municípios, bem como em localizar suas normas, ou mesmo compreender a expressão "gestão democrática". Nessas circunstâncias, levantase a hipótese de que podem ser muito mais princípios, espaços e mecanismos formais, postos nas normas municipais para a devida consonância com as normas nacionais, mas não materializados em âmbito local.

\section{DINÂMICAS DE PARTICIPAÇÃO NAS COMUNIDADES ESCOLARES NA PERSPECTIVA DE CONSELHEIROS}

Em relação às características das dinâmicas de participação nas comunidades escolares nos municípios pesquisados, especificamente quanto aos espaços/mecanismos ${ }^{4}$ institucionalizados de participação, conhecidos pelos sujeitos pesquisados, como CME, CE, FME, Conferência Municipal de Educação (ou equivalente), grêmios estudantis, Associações de Pais e Mestres (APM) e outro(s), observam-se a prevalência do CME e uma parca organização dos estudantes, como mostram os dados da Tabela 1.

\section{Tabela 1 - Espaços institucionalizados de participação conhecidos pelos sujeitos da pesquisa}

\begin{tabular}{|c|c|c|}
\hline Espaços & Quantidade & Porcentual \\
\hline Conselho Municipal de Educação & 36 & $72 \%$ \\
\hline Associação de Pais e Professores & 29 & $58 \%$ \\
\hline Conselhos Escolares & 28 & $56 \%$ \\
\hline Fórum Municipal de Educação & 27 & $54 \%$ \\
\hline Conferência Municipal de Educação (ou equivalente) & 23 & $43 \%$ \\
\hline Grêmios estudantis & 10 & $20 \%$ \\
\hline Outro - Descreva & 3 & $6 \%$ \\
\hline
\end{tabular}

Fonte: Questionários Rede MAPA (2018).

4 Espaços aqui entendido como "lugar físico, lugar, local, recinto, superfície, ambiente para momentos coletivos". 
Os sujeitos da pesquisa, quando questionados a respeito dos espaços institucionalizados de participação que funcionam adequadamente, também afirmaram ser o CME, e, da mesma forma, observa-se o desconhecimento do grêmio estudantil, como demonstra a Tabela 2.

\section{Tabela 2 - Espaços institucionalizados de participação que funcionam adequadamente}

\begin{tabular}{|c|c|c|}
\hline Espaços & Quantidade & Porcentual \\
\hline Conselho Municipal de Educação & 29 & $58 \%$ \\
\hline Fórum Municipal de Educação & 23 & $46 \%$ \\
\hline Associações de Pais e Professores & 23 & $43 \%$ \\
\hline Conselhos Escolares & 20 & $40 \%$ \\
\hline Conferência Municipal de Educação ou equivalente & 12 & $24 \%$ \\
\hline Grêmios estudantis & 5 & $10 \%$ \\
\hline Outro - Descreva & 1 & $2 \%$ \\
\hline
\end{tabular}

Fonte: Questionários Rede MAPA (2018).

Em relação aos mecanismos ${ }^{5}$ institucionalizados de participação, conhecidos pelos sujeitos investigados, como o projeto político-pedagógico (PPP), PME, eleição direta para diretores das escolas da rede municipal; ou outra forma de indicação de nomes para diretores das escolas da rede municipal e outro(s), sobressaem os documentos de planejamento da educação e da escola. Outro aspecto a ser observado é o percentual maior de indicação dos diretores das escolas, e não a eleição direta, como demonstrado na Tabela 3.

\section{Tabela 3 - Mecanismos institucionalizados de participação conhecidos pelos sujeitos da pesquisa}

\begin{tabular}{|c|c|c|}
\hline Mecanismos & Quantidade & Porcentual \\
\hline Projetos político-pedagógicos & 33 & $66 \%$ \\
\hline Plano Municipal de Educação & 33 & $66 \%$ \\
\hline Outra forma de indicação de nomes para diretores das escolas da rede & 14 & $28 \%$ \\
\hline Eleição direta para diretores das escolas da rede municipal & 11 & $22 \%$ \\
\hline Outro - Descreva & 0 & $0 \%$ \\
\hline
\end{tabular}

Fonte: Questionários Rede MAPA (2018).

5 "Mecanismo" é usado aqui no sentido de : "organização de um todo, processo no qual se pode determinar, pela análise, uma série defases subordinadas e dependentes uma da outra. 
Quando questionados a respeito dos mecanismos institucionalizados de participação que funcionam adequadamente, os conselheiros investigados ressaltaram, da mesma forma, os documentos de planejamento. Entretanto, nessa questão, responderam funcionar a eleição direta, em contradição com as respostas acerca da existência desse mecanismo, como explicitado na Tabela 4.

\section{Tabela 4 - Mecanismos institucionalizados de participação que funcionam adequadamente}

\begin{tabular}{|c|c|c|}
\hline Mecanismos & Quantidade & Porcentual \\
\hline Projetos Políticos Pedagógicos & 30 & $60 \%$ \\
\hline Plano Municipal de Educação & 25 & $50 \%$ \\
\hline Eleição direta para diretores das escolas da rede municipal & 10 & $20 \%$ \\
\hline Outra forma de indicação de nomes para diretores das escolas da rede municipal & 4 & $8 \%$ \\
\hline Outro - Descreva & 0 & $0 \%$ \\
\hline
\end{tabular}

Fonte: Questionários Rede MAPA (2018).

Das análises dos dados e das informações da pesquisa em campo, observase que a maioria $(57 \%)$ dos representantes docentes nos CME, que responderam aos questionários, encontra-se na função de conselheiros há mais de três anos e não receberam formação para tal atuação (REDE MAPA, 2018a).

Apreende-se, também, a realização de Conferências Municipais de Educação na maioria dos municípios; o FME e os grêmios estudantis ainda não fazem parte dos espaços de participação nas comunidades escolares investigadas; e nem a eleição direta para diretores das escolas da rede municipal ou outra forma de indicação de nomes para a função são mecanismos de gestão democrática (REDE MAPA, 2018a).

Sobre oportunidades para a participação da sociedade nos processos de tomada de decisão a respeito de assuntos da educação pública municipal, há unanimidade quanto à existência de algumas oportunidades adequadas, seguida pelas opções: muitas oportunidades adequadas; muitas oportunidades, mas são parcialmente adequadas; muitas oportunidades, mas são inadequadas; algumas oportunidades adequadas; algumas oportunidades, mas são parcialmente adequadas; algumas oportunidades, mas são inadequadas; e inexistem oportunidades (REDE MAPA, 2018a).

Em se tratando da efetividade dos espaços e dos mecanismos de participação, os representantes docentes apontaram vários indicadores, parecendo comprovar tal efetividade, como a atuação do CME e a necessidade de conhecimento da realidade (REDE MAPA, 2018a). 
Dos 36 municípios cujos representantes docentes responderam aos questionários, apenas seis indicaram outros espaços e mecanismos de participação para reforçar a democratização da gestão educacional, tendo como função a fiscalização e a organização dos profissionais da educação (REDE MAPA, 2018a). Como desafios a serem superados para o avanço na democratização da gestão da educação pública na educação básica, destacam-se entre as respostas: participação popular; acompanhamento, fiscalização e execução dos planos e projetos; maior autonomia dos conselhos; melhor planejamento; implementação de eleições diretas; e ampliação dos espaços físicos, possibilitando acesso à tecnologia e laboratórios de ensino (REDE MAPA, 2018a).

A maioria dos representantes da sociedade civil nos CME, que responderam aos questionários, é: funcionário público municipal; está na função de conselheiros até dois anos; e não recebeu formação para atuar na função (REDE MAPA, 2018b).

Em relação aos espaços de participação, sobressaem nas respostas: o CME, os CE, o FME, as Conferências Municipais de Educação e as associações de pais e professores. Também, neste conjunto de respondentes, o FME e os grêmios estudantis não fazem parte das dinâmicas das comunidades escolares investigadas (REDE MAPA, 2018b).

Como mecanismos, todos indicaram o PPP e o PME. A eleição direta para diretores das escolas da rede municipal também não aparece como mecanismo de gestão democrática (REDE MAPA, 2018b).

A respeito de oportunidades para a participação da sociedade nos processos de tomada de decisão acerca de assuntos da educação pública municipal, sobressai a resposta de existência de algumas oportunidades adequadas, seguida de muitas oportunidades adequadas, sendo que nenhum respondente indicou alternativas, ou seja: muitas oportunidades, mas são parcialmente adequadas; muitas oportunidades, mas são inadequadas; algumas oportunidades adequadas; algumas oportunidades, mas são parcialmente adequadas; algumas oportunidades, mas são inadequadas; e inexistem oportunidades (REDE MAPA, 2018b).

Das justificativas, destacam-se as ideias de que a sociedade não participa, assim como da pouca autonomia no processo de tomada de decisões (REDE MAPA, 2018b).

Uma resposta chamou a atenção, pois apresenta o conceito de participação, mas como induzida: "Percebe-se uma grande participação da sociedade, sempre que solicitada.” (REDE MAPA, 2018b).

No que tange às razões que justificam a efetividade dos espaços e mecanismos de participação, os respondentes parecem ter confundido a pergunta e destacam como necessidades: maior participação e interesse; participação no 
processo educacional; PPP bem elaborado e executado de forma democrática. Uma das respostas desvela o cumprimento parcial do PME. Por outro lado, e parecendo contraditório com os desafios a democratização da gestão, também, há respostas enfatizando que há "autonomia da educação municipal; participação da sociedade; e acompanhamento social." (REDE MAPA, 2018b).

Os representantes da sociedade civil, ao tratarem de outros espaços e mecanismos de participação para reforçar a democratização da gestão educacional, em sua maioria, se limitaram nas respostas ao indicar o "talvez". Um apontou a descentralização de recurso e outro o processo seletivo para diretores e coordenadores (REDE MAPA, 2018b).

No que concerne aos desafios à democratização da gestão do ensino, as respostas reiteram desafios históricos na educação, como transparência; maior participação social; mais recursos financeiros para a educação; descentralização de recursos; autonomia financeira e de gestão de recursos pela Secretaria de Educação; realização de concurso público; eliminação das indicações políticas; eleição direta para diretor; CME efetivo (REDE MAPA, 2018b).

Das análises dos questionários, resultantes da segunda etapa da pesquisa, insistem-se nas análises da primeira etapa, de que, tomando como pressupostos as normas nacionais da educação (BRASIL, 1988, 1996, 2014), os municípios apresentam importantes espaços e mecanismos, mas parcos, por representarem uma gestão democrática mais como método, não como princípio e método.

Por consequência, as características das dinâmicas de participação nas comunidades escolares investigadas podem não ser suficientes para a materialização da gestão democrática em seu sentido estrito, considerando a participação sociopolítica, reforçando as ideias de Poli e Lagares (2017, p. 844): "Pelo contexto de dilemas, as condições de participação não serão dadas. Antes, devem ser construídas no processo de enfrentamento, repelindo discursos e atitudes imobilizadoras e conformistas." Assim sendo, urge a necessidade de se compreender o significado e os sentidos distintos, diversos e contraditórios de participação.

A gestão democrática da educação, do ponto de vista normativo, não se assenta na perspectiva do gerencialismo, porém, observa-se nos resultados da pesquisa um tensionamento entre o princípio e o método democráticos (SOUZA, 2009). Dessa forma, e considerando as diferentes disputadas e significações envolvendo os termos "democracia", "participação" e "gestão democrática da educação", reitera-se a preocupação de Souza (2009, p.136): 
[...] a pesquisa no campo da gestão escolar/educacional carece de uma discussão conceitual mais aprofundada sobre a gestão democrática (SOUZA, 2007) e de operar com esses conceitos de maneira menos normativa (SOUZA, 2006), ainda que parte do compromisso social do pesquisador resida justamente em apontar alternativas, mas parece mesmo necessário buscar tomar a teoria como hipótese. (BRANDÃO, 2002).

Acredita-se que os postulados apresentados por Lima (2013, p. 27) subsidiem a reflexão sobre os resultados da pesquisa aqui apresentada:

\begin{abstract}
Primeiro postulado: a ideia é tratar a análise da gestão democrática a partir daquilo que foi preconizado/idealizado como gestão democrática (tese), aquilo que temos, ou seja, o que tem sido a gestão (antítese), e, a partir desses elementos, compor algumas ideias de um vir a ser, aquilo que entendemos e queremos com a gestão democrática (síntese). Segundo postulado: a gestão democrática, como a democracia, é um processo, e por assim ser não é produto acabado. E, por estar em constante construção, oscila entre as possibilidades participativas e os limites centralizadores. Terceiro postulado: existem três elementos básicos para a construção da gestão democrática: a participação, a descentralização e a autonomia sendo que a descentralização contempla os preceitos da participação e da autonomia. Um processo de descentralização articula o poder político de projetar e planejar de forma autônoma e participativa o ente descentralizado, aquilo que conhecemos como poder local. Não existe, portanto, descentralização sem autonomia e sem participação. Tampouco gestão democrática.
\end{abstract}

Por ser a gestão democrática um "produto" em instituição, ainda que sob o imperativo do princípio nas normas e a defesa de sua materialização pelo campo teórico democrático popular, carece de aprofundamento conceitual, iniciando pelos próprios conceitos de democracia, participação e autonomia, até os limites e as possibilidades da gestão com essa concepção teórica e política na sociedade em que se vive.

\title{
CONSIDERAÇÕES FINAIS
}

Este estudo teve o intuito de examinar o quadro normativo e as condições político-institucionais estabelecidas por governos municipais com SME no Tocantins, para a gestão democrática da educação pública no âmbito dos seus sistemas e características das dinâmicas de participação nas comunidades escolares nos municípios, entre os anos de 2007 a 2018. A investigação demonstrou que a regulação da gestão democrática nos sistemas pesquisados por vezes não caminha mais em consonância com elementos tecnicistas, e sim para a afirmação de uma perspectiva de gestão ancorada na defesa da participação dos sujeitos. 
Mas por que por vezes? Porque a pesquisa encontrou, também, elementos da gestão burocrática e gerencial, como as indicações políticas para a gestão das escolas, a baixa credibilidade na participação dos alunos com um número mínimo de grêmios estudantis, a necessidade da indução da participação social.

Embora a pesquisa tenha apreendido a presença de princípios/ espaços/ mecanismos essenciais à gestão democrática, como disposto pelas normas nacionais, evidenciando, em parte, uma consonância com a LDB e o PNE, não é possível concluir que os processos sejam democráticos; desnudando, assim, o tensionamento entre o princípio e o método democráticos.

Evidencia, então, a necessidade de aprofundamentos a respeito do conceito de gestão democrática, bem como de análises se os princípios/ espaços/ mecanismos estão presentes em normas municipais mais para guardar a consonância legal.

\section{REFERÊNCIAS}

BARDIN, Laurence. Análise de conteúdo. Lisboa: Edições 70, LDA, 2009.

BORDIGNON, Genuíno; GRACINDO, Regina V. Gestão da educação: o município e a escola. In. FERREIRA. Naura S. C.; AGUIAR. Márcia Angela da S. (Org.). Gestão da educação: impasses, perspectivas e compromissos, São Paulo: Cortez, 2008.

BRASIL. Congresso Nacional. [Constituição (1988)]. Constituição da República do Brasil de 1988. Brasília, DF, 1988.

BRASIL. Congresso Nacional. Lei no 13.005, de 25 de junho de 2014. Aprova o Plano Nacional de Educação (PNE) e dá outras providências. Brasília, DF: Câmara dos Deputados, 2014.

BRASIL. Congresso Nacional. Lei $\mathbf{n}^{\mathbf{0}} \mathbf{1 0 . 1 7 2}$, de 09 de janeiro de 2001. Aprova o Plano Nacional de Educação (PNE) e dá outras providências. Brasília, DF: Câmara dos Deputados, 2001.

BRASIL. Congresso Nacional. Lei no 9.394, de 20 de dezembro de 1996. Estabelece as Diretrizes e Bases da Educação Nacional (LDB). Brasília, DF: Câmara dos Deputados, 1996. 
DENZIN, Norman K; LINCOLN, Yvonna S. O planejamento da pesquisa qualitativa: teorias e abordagens. Porto Alegre: Artmed, 2006.

FREIRE, Juciley Silva Evangelista. Participação e educação: concepções presentes nos estudos da Revista Educação \& Sociedade (1978-2010). Goiânia: UFG/Programa de Pós-Graduação em Educação da Faculdade de Educação, 2011.

LAGARES, Rosilene; SANTOS, Leonardo Victor dos. Gestão da educação municipal na Microrregião Dianópolis-Tocantins: parcas condições institucionais para democracia. In: SEMINÁRIO NACIONAL DA REDE MAPA. 2., 2017, Joaçaba. Anais [...], Joaçaba: Universidade do Oeste de Santa Catarina (Unoesc), 2017.

LEMOS, Patrícia de Mello Gomes Linhares. Aumentar as paredes ou derrubar os muros?: gestão democrática nos planos de educação dos munícipios do Tocantins. 2017. (Trabalho de Conclusão de Curso de Pedagogia) - Universidade Federal do Tocantins, Palmas, 2017.

LIMA, Antônio Bosco de. Adeus à Gestão (Escolar) Democrática. Revista @ rquivo Brasileiro de Educação, Belo Horizonte, v. 1, n. 1, p. 27-50, 2013.

LIMA; Telma Cristiane Sasso de; MIOTO, Regina Célia Tamaso. Procedimentos metodológicos na construção do conhecimento científico: a pesquisa bibliográfica. Rev. Katál, Florianópolis, v. 10, n. esp., p. 37-45, 2007.

NARDI, Elton Luiz. Projeto de Pesquisa: gestão democrática do ensino público: mapeamento das bases normativas e das condições político-institucionais dos sistemas municipais de ensino. Universidade do Oeste de Santa Catarina (Unoesc), 2014.

POLI, Luzenir, LAGARES, Rosilene. Dilemas da Gestão Democrática da Educação Frente ao contexto da Nova Gestão Pública. RBPAE, v. 33, n. 3, p. 835 - 849, set./dez. 2017.

REDE MAPA. Questionários docentes. Membro do Conselho Municipal de Educação - Representante do segmento dos docentes da rede municipal de ensino. Tocantins, 2018a. 
REDE MAPA. Questionários sociedade civil. Membro do Conselho Municipal de Educação - Representante da sociedade civil. Tocantins, 2018b.

SANDER, Benno. Gestão educacional: concepções em disputa. Revista Retratos da Escola, Brasília, v. 3, n. 4, p. 69-80, jan./jun. 2009.

SHIROMA, Eneida Oto; CAMPOS, Roselane Fátima; GARCIA, Rosalba Maria Cardoso. Decifrar textos para compreender a política: subsídios teóricometodológicos para análise de documentos. Perspectiva, Florianópolis, v. 23, n. 2, p. 427-446, jul./dez. 2005.

SOUZA, Ângelo Ricardo de. Explorando e construindo um conceito de gestão escolar democrática. Educação em Revista, Belo Horizonte, v. 25, n. 3, p.123140, dez. 2009.

\section{Rosilene Lagares}

Doutora em Educação (UFG), com estágio pós-doutoral em Educação (UNOESC), Professora Associada da Universidade Federal do Tocantins do Campus de Palmas, no Curso de Pedagogia e no Programa de Pós-Graduação em Educação, Professora do Programa de Pós-Graduação em Educação na Amazônia (EducaNorte-Doutorado), Coordenadora do Subgrupo de Estudos, Pesquisa e Extensão em Educação Municipal (EpeEM) e do Observatório de Sistemas e Planos de Educação (ObSPE), E-mail: roselagares@uft.edu.br

\section{Katia Cristina Ferreira Custódio Brito}

Doutora em Educação (UFSCAR), Professora Titular da Universidade Federal do Tocantins do Campus de Palmas, no Curso de Pedagogia e no Programa de Pós-Graduação em Educação, Pesquisadora do Subgrupo de Estudos, Pesquisa e Extensão em Educação Municipal (EpeEM) e do Observatório de Sistemas e Planos de Educação (ObSPE), E-mail: katiacristina@uft.edu.br

\section{Meire Lúcia Andrade da Silva}

Doutoranda em Educação (UFG), Mestre em Educação (UFT), Professora do Sistema Municipal de Ensino de Gurupi-Tocantins, Pesquisadora do Subgrupo de Estudos, Pesquisa e Extensão em Educação Municipal (EpeEM) e do Observatório de Sistemas e Planos de Educação (ObSPE), E-mail: melucia26@ hotmail.com 